\title{
Resilient cooling of buildings to protect against heat waves and power outages: Key concepts and definition
}

\author{
Shady Attia ${ }^{\mathrm{a}, *}$, Ronnen Levinson ${ }^{\mathrm{b}}$, Eileen Ndongo ${ }^{\mathrm{a}, \mathrm{c}}$, Peter Holzer ${ }^{\mathrm{d}}$, Ongun Berk Kazanci ${ }^{\mathrm{e}}$, \\ Shabnam Homaei ${ }^{f}$, Chen Zhang ${ }^{g}$, Bjarne W. Olesen ${ }^{\mathrm{e}}$, Dahai Qi ${ }^{\mathrm{h}}$, Mohamed Hamdy ${ }^{\mathrm{f}}$, Per Heiselberg ${ }^{\mathrm{g}}$ \\ a Sustainable Building Design Lab, Department UEE, Applied Sciences, University of Liège, Belgium \\ ${ }^{\mathrm{b}}$ Heat Island Group, Lawrence Berkeley National Laboratory, Berkeley, CA, USA \\ ${ }^{\mathrm{c}}$ EPF Graduate School of Engineering, Montpellier, France \\ ${ }^{\mathrm{d}}$ Institute of Building Research $\mathcal{E}$ Innovation, Vienna, Austria \\ e International Centre for Indoor Environment and Energy - ICIEE, Technical University of Denmark, Denmark \\ ${ }^{\mathrm{f}}$ Department of Civil and Environmental Engineering, NTNU Norwegian University of Science and Technology, Trondheim, Norway \\ ${ }^{\mathrm{g}}$ Department of the Built Environment, Aalborg University, Denmark \\ ${ }^{\mathrm{h}}$ Department of Civil and Building Engineering, Université de Sherbrook, Canada
}

\section{A R T I C L E I N F O}

\section{Article history:}

Received 14 June 2020

Revised 19 January 2021

Accepted 1 March 2021

Available online 6 March 2021

\section{Keywords:}

Overheating

Resilience

Resistance

Robustness

Recovery

Thermal comfort

Climate change

Cooling technologies

\begin{abstract}
A B S T R A C T
The concept of climate resilience has gained extensive international attention during the last few years and is now seen as the future target for building cooling design. However, before being fully implemented in building design, the concept requires a clear and consistent definition and a commonly agreed framework of key concepts. The most critical issues that should be given special attention before developing a new definition for resilient cooling of buildings are (1) the disruptions or the associated climatic shocks to protect against, (2) the scale of the built domain, (3) the timeline of resilience, (4) the events of disruption, (5) the stages of resilience, (6) the indoor climate limits and critical comfort conditions, and (7) the influencing factors of resilient cooling of buildings. This paper focuses on a scoping review of the most of the existing resilience definitions and the various approaches, found in 90 documents, towards possible resilient buildings. In conclusion, the paper suggests a definition and a set of criteria -vulnerability, resistance, robustness, and recoverability - that can help to develop intrinsic performance-driven indicators and functions of passive and active cooling solutions in buildings against two disruptors of indoor thermal environmental quality-heat waves and power outages.
\end{abstract}

(c) 2021 Elsevier B.V. All rights reserved.

\section{Introduction}

The resilience of the built environment against climate change impacts and associated disruptions is an important topic that has received increasing attention in recent years [1]. Resilience is a central feature of the United Nations (UN) Sustainability Development Goals (SDGs) and is reflected in a range of SDG targets [2]. According to the UN General Assembly Resolution 71/276 [3], the term "resilience" describes "the ability of a system, community or society exposed to hazards to resist, absorb, accommodate, adapt to, transform and recover from the effects of a hazard in a timely and efficient manner, including through the preservation and restoration of its essential basic structures and functions through risk management." The European Green Deal identified

\footnotetext{
* Corresponding author at: Sustainable Building Design Lab, Department UEE, Applied Sciences, University of Liège, Belgium.

E-mail address: shady.attia@uliege.be (S. Attia).
}

climate-proof buildings and low-carbon buildings as key levers to achieve a resilient and carbon-neutral continent [4]. The need for resilient building design and construction is urgent to anticipate climate change and disruptions caused by weather extremes, increasing carbon emissions, and resource depletion [5]. Our well-being depends on reducing the carbon emissions in our built environment and other sectors [6]. While solving the root-cause problem of climate change, we need to address its effects. Avoiding excessive temperatures induced by overheating is one of the most critical challenges that the building industry will face worldwide in the coming decades $[7,8]$.

Increasing electricity demand during heat stresses can lead to blackouts and grid failures. This can leave buildings out of thermal comfort range and threaten the lives of vulnerable people at risk, as happened during the 2003 Europe heat wave [9]. As building disruptions may have severe and long-term economic impacts, resilient building cooling solutions are an essential strategy to mitigate 
threats to occupants [10]. There is an urgent need for resilient cooling solutions in buildings to keep comfort despite extreme weather events due to climate change [11]. Meanwhile, the use of fuelintensive mechanical cooling should be reduced to slow climate change [12]. Greenhouse gas (GHG) emissions from buildings air conditioning stand at around 210-460 gigatonnes of carbon dioxide equivalent $\left(\mathrm{GtCO}_{2} \mathrm{e}\right)$ over the next four decades, based on 2018 levels [13].

It is of principal importance to define buildings' resilient cooling to maintain indoor environmental quality against unexpected events, e.g., extreme weather conditions, heat waves, power outages, etc. However, the definition of resilience and resilient cooling is challenging and complex [14]. Research on resilience associated with human-nature interactions is still in an explorative stage with few practical methods for real-world applications $[15,16]$.

This article presents the main concepts of resilience. It proposes a definition of resilient cooling of buildings based on the discussion taking place in the International Energy Agency (IEA) - Energy in Buildings and Communities Programme (EBC) research project “Annex 80: Resilient Cooling of Buildings" [11]. The essence of this paper is to define resilience against overheating and power outage. It seeks to answer the following research questions:

- What are the existing concepts of resilience in the built environment?

- How to define resilient cooling of buildings?

The article presents a definition framework based on reviewing almost 90 studies of resilience, including RELi 2.0 Rating Guidelines for Resilient Design and Construction [17]. One of the challenges of this study is to define resilience on the building scale beyond what is present in literature, which mainly addresses the definition of resilience on an urban scale. Most of the studies we reviewed investigated the term "resilience" on the urban scale against disruptions such as hurricanes, flooding, earthquakes, and a long duration [18]. In this context, most studies tend to address the urban scale's resilience for an extended period with less focus on the building scale [18]. The proliferation of urban- or community-scale investigations limits attention paid to indoor environmental quality and overheating buildings' problems. One interpretation for that could be that heat waves and power outages are specific shock events that occur briefly on a few summer days. However, we found many studies confirming that climate change increases the frequency and magnitude of heat waves, making heat waves rise in the ranking of the most significant disruptions in the built environment [19]. This reinforces the importance of resilient cooling as an integral approach for building design and operation concerning comfort (including indoor environmental quality), carbon neutrality, and environmental friendliness [6].

\section{Methodology}

Fig. 1 shows the research methodology of this study, including its conceptual framework. The methodology is similar to that used by Attia to define main concepts and definitions of adaptive facades [20,21]. Our research methodology is qualitative and relies on the literature review, focus group discussions, and individuals' follow-up discussions. The research methodology of this study has four significant steps, each detailed in the following sections.

\subsection{Literature review}

A literature review was conducted, aiming to define resilience against different climate change associated disruptions in the built

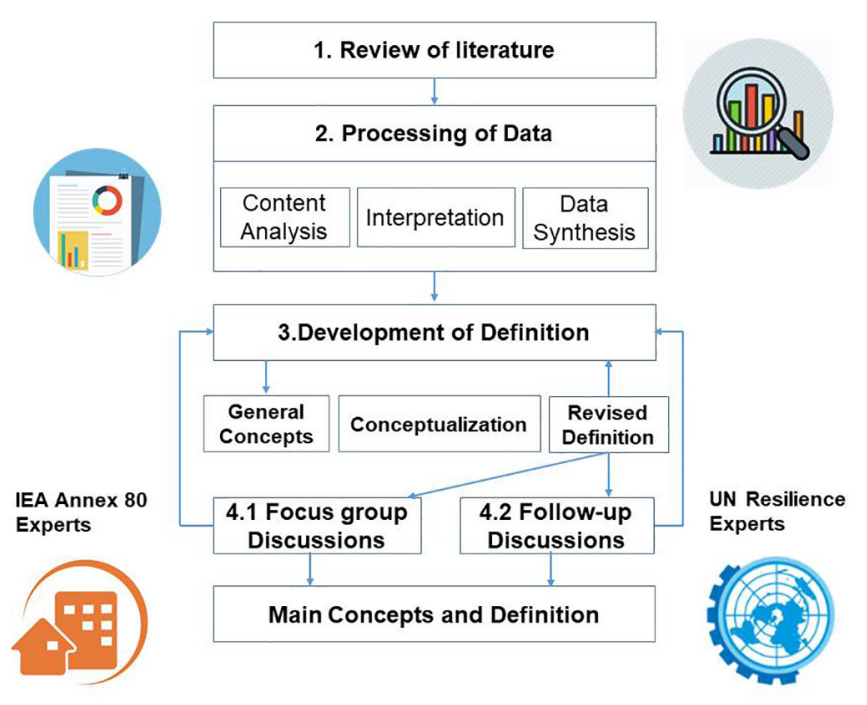

Fig. 1. Study conceptual framework.

environment worldwide. The publications included scientific journal articles, reports, books, building rating systems, and grey literature (government reports, policy statements, and papers. We opted for large databases and quality web sources with complete bibliographic data. Our initial Scopus and Web of Science research resulted in almost 90 publications relevant to the built environment's resilience and resilience criteria. To examine the definitions of resilience and the associated resilience criteria such as vulnerability, resistance, robustness, and recoverability, we surveyed resilience in ecology, resilience in engineering, and resilience in psychology as inclusion criteria. These domains cover the body of knowledge and discourse concerning resilience in general. We then narrowed the research scope to focus on the overheating and power outage disruptions and the resilience of cooling strategies and technologies in buildings. The exclusion criteria were twofold, aiming to eliminate publications that define resilience on an urban scale and infrastructure. The exclusion criteria included terms such as "city", "urban", "structure", "infrastructure", and "flooding". The search language was mainly English and looked back to 1995, in which the term resilience first appeared in literature related to the built environment, until 2020. The publication information was imported to the software HistCite 12.3.17 for analysis and grouped into two categories [22]: resilience on the building scale and resilience on the urban scale. The results of the literature review are presented in Section 3 and Appendix A.

\subsection{Data processing}

We analyzed the content of every identified article's full text and developed an analysis protocol and coding schema to record its content attributes. The entire text of the full article was read multiple times as they search for coding words was completed by the coders (authors). Coding is a way of indexing or categorizing the text to establish a framework of its themes [23]. We used the framework method commonly used to manage and analyze qualitative data in health research $[24,25]$. The framework method involves reading the manuscripts carefully and applying a code or label that describes important phrases or paragraphs. The documents are labeled and systematically to develop a dataset of codes. After coding the manuscripts, the codes were compared and classified. Codes were then grouped together in categories. After several categorization iterations, an analytical framework or structure for the main domain and concepts was created under which the codes 
and labels are grouped. With the help of ATLAS.ti software (version 9 ) the framework is charted grouping all codes, concepts and categories [26]. The tagging system summarizes and interprets the manuscripts interrogating the theoretical concepts and the connection between categories in a structured way. A detailed description of text processing can be found in Attia's videos [27,28].

\subsection{Development of definition}

We used the framework method for the definition development, which is the most commonly used technique for the management and analysis of qualitative data in health research [24,25]. The framework method allows systematic analysis of the text data to produce highly structured outputs and summarized data. It can also compare and identify patterns, relevant themes, and contradictory data [24]. We categorized the codes (resilience concepts) by theme. Our classification resulted in four concepts that define the resilient cooling of buildings.

\subsection{Focus group and follow-up-discussions}

Qualitative research is primarily a subjective approach as it seeks to understand human perceptions and judgments. However, it remains a reliable exploratory scientific method if bias is avoided. The suggested definition validated through focus group discussions to provide consistent and dependable results. Several validation measures were implemented, including member checking, memo logs, and peer examination following the work of Attia [29] and Attia et al. [21]. The study validation allowed emphasizing credibility and strengthening the relevance of the conducted study and results. Focus groups were convened during IEA-EBC Annex 80 's first expert meeting in Vienna, Austria (21 October 2019) and during its second expert meeting, held online (21 April 2020). Each focus group comprised of 15 people. IEA-EBC Annex 80 members aim to support a rapid transition to an environment where resilient, low energy and low carbon cooling systems are the mainstream and preferred solutions for cooling and overheating issues in buildings [11]. The invited experts for the focusgroup discussion represented the scientific and professional experts in the field of building performance assessment and comfort. A list of the IEA-EBC Annex 80 participants can be found on the Annex website [30]. The focus group discussions' goal was to validate the suggested definition and main associated criteria [29].

Follow-up discussions with RELi steering committee members and UN resilience experts helped articulate and validated the framework and included detailed elaboration of some criteria. The RELi Rating System is a holistic, resiliencebased rating system that combines innovative design criteria with the latest integrative design processes for next-generation neighborhoods, buildings, homes, and infrastructure (see further explanation Section 3.3). The follow-up discussions took place between the first authors and some of the co-authors via teleconference and emails.

\section{General concepts of resilience}

The definitions of resilience concern with the interplay of continuity and change of objects/systems subject to internal or external disruption(s). Whatever the field of application of the resilience concept, the study of resilience entails adapting to crisis associated with the assumption of vulnerability in the context of climate change [31]. Vulnerability has been used as the "flip side" of resilience [32]. Some researchers separate resilience and vulnerability [33], while others consider resilience related to one of the components of vulnerability [34]. In the following two subsections, we explain resilience concepts in different domains and review papers that assess resilient comfort in buildings.

\subsection{Resilience in different domains}

The concept of resilience varies by discipline [35]. The first definition, found in ecological literature, is a system's ability to absorb a shock without changing its pre-shock structure, identity, and function. Holling [36] defined resilience to disruptions in ecosystems. His resilience concept assumes that the system's absorptive resilience or "ability to bounce back" can handle shocks and find an alternative (equilibrium) state or form that is less good than the system's pre-shock state.

The second definition of resilience, found in the behavioral psychology literature, focuses on positive adaptability resilience or “ability to absorb" [37]. Resilience is defined as individuals' coping capacity to maintain or regain psycho-pathological well-being following trauma, personal stress, or crisis [35]. In this definition, individuals are expected to demonstrate dynamic self-renewal and adjustment capacity to neutralize the shock and its impacts.

The third definition of resilience, found in the engineering and economics literature, is focused on the ability to "bounce forward" or "recover; fast following a disruption [35]. This was termed "engineering resilience" due to the human-made nature of engineering [36]. It is defined as "how fast a system that has been displaced from equilibrium by a disturbance or shock returns to that equilibrium and continues performing." This interpretation was also found in the physical sciences and economics literature. This definition of resilience led some authors to refer to it as "evolutionary resilience" due to the ability of the system to "bounce forward" rather than just absorb the shock or "bounce back" [38-40]. Table 1 summarizes the different definitions and concepts of resilience under three categories.

\subsection{Resilience as "bounce forward" from shocks}

There is a plethora of studies that employed the term "resilience'. However, very few studies have defined the term 'resilience' in the built environment [42]. Therefore, we deliberately chose the third definition of resilience (see Table 1 ). The third definition of resilience is already used differently by researchers and professionals in different engineering domains (structural and energy engineering) and is focused on the ability to "bounce back" or recover following a disruption of some kind [38,43,44]. As shown in Fig. 2, the definition of resilience in engineering and economy is a process that involves several elements. The first element is vulnerability (the sensitivity of a building system to different types of shocks). According to literature, vulnerability is a central concept in climate change research. Vulnerability describes the system associated with hazards of concern and attributes of concern $[45,46]$. The UN general definitions define vulnerability

Table 1

Different concepts and definitions of resilience in different domains [35]

\begin{tabular}{cl}
\hline Fields & Definition Interpretations \\
\hline $\begin{array}{c}\text { In ecology:Resilience is the "ability to } \\
\text { absorb shocks" or" bounce back" }\end{array}$ & $\begin{array}{l}\text { Ability of an ecosystem to rearrange } \\
\text { its organization outside of its } \\
\text { equilibrium state to another one } \\
\text { when facing a perturbation [36]. }\end{array}$ \\
$\begin{array}{cl}\text { In psychology:Resilience is "positive } \\
\text { adaptability" in anticipation of/in } \\
\text { response to shocks }\end{array}$ & $\begin{array}{l}\text { Capacity of an individual to endure } \\
\text { and develop in the context of adverse } \\
\text { conditions and to recover [37]. }\end{array}$ \\
$\begin{array}{c}\text { In engineering and economics: } \\
\text { Resilience the ability to "bounce } \\
\text { forward" from shocks }\end{array}$ & $\begin{array}{l}\text { Ability of a system to resist } \\
\text { perturbations outside of its } \\
\text { equilibrium state and its speed to } \\
\text { come back to it [35,41]. }\end{array}$ \\
\end{tabular}




\section{Stages of Resilience}

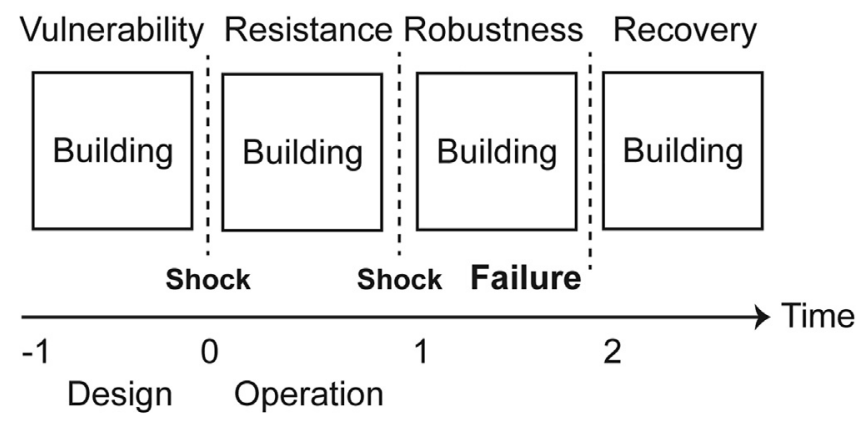

Fig. 2. The stages and timeline of the resilience process.

as risks "expected losses [...] resulting from interactions between natural or human-induced hazards and vulnerable conditions" [47]. The second element is resistance (the building system's ability to maintain the initial design conditions). The third element is robustness (how the building system, including occupants, adjusts and adapts to shocks under critical performance conditions). The fourth element is recoverability (the extent and nature of recovery from shocks). If the building cooling design involves a vulnerability assessment, it can resist shocks, then falls under the influence of a shock and recovers from the shock; only then we can call it a resilient.

To define a building or system as resilient, it must be vulnerable (sensitive) to disruptions or shocks and experience failure. Failure is essential in any definition of resilience because the latter is built upon it. A failure can be temporary or permanent and can partial or full. The failure to protect occupants against heat waves or power outages, resulting in heat-related deaths or morbidity, are examples of building failures [19]. Unfortunately, several studies in the field of building engineering investigated the robustness of the building's performance against heat waves without addressing the broader definition of resilience and its stages illustrated in Fig. 2 [48-50].

Thus, there is a lack of understanding of the term "resilience" and the conditions and stages associated with this complex term. The fundamental definition of resilience necessitates the occurrence of a shock. Only the presence of a shock can ascertain whether, and to what extent, the robustness (adaptation) of a system or building has imbued it with resilience [38].

\subsection{Resilience in the built environment}

The literature about resilience in the built environment can be classified by scale-urban or building.

Ernsstson et al. [51] published one of the earliest studies defining urban resilience within human-dominated ecosystems. Using three case cities, the study explored the resilience of urban governance concerning ecosystem services. Similarly, Meerow et al. [52] proposed a general definition of urban resilience without focusing on any specific disruption in the built environment. In contrast, Godschalk [53] focused on urban hazards in cities and specifically on terrorism. The study was initiated due to the terrorist attack on the World Trade Center in September 2001 in New York and presented resilience in this context.

Liao [15] presented a definition of urban resilience addressing floods and the surrogate measure of percent floodable area for assessing potential to flood. Stead [54] evaluated Rotterdam's resilience (Netherlands) with a focus on water management and climate change. Sharifi \& Yamagata [55] developed a framework for assessing urban energy resilience, identifying planning and design criteria, and examining these criteria' relationshiBased on their framework, to be resilient, and urban energy system needs to be capable of "planning and preparing for," "absorbing," "recovering from," and "adapting to" future adverse events.

The previous studies addressed resilience and vulnerability on the urban scale. Other reviewed studies have addressed the concept of resilience for individual buildings. Most focused on blast resilience, seismic resilience, and hurricane or wind resilience. Takewaki et al. [43] sought to reduce the unexpected incidents in building structural design and define robustness and resilience against earthquakes in buildings. Cormie et al. [57] assessed the whole-building response against blasts and the influence of the building form and façade. Tokgoz \& Gheorghe [56] quantified the resilience of residential buildings against hurricane winds.

Lomas and Ji [58] published one of the earliest studies on thermal resilience in buildings. In a special issue of Building and Environment, Lomas \& Giridharan [59] measured internal temperatures and thermal resilience to climate change of freerunning hospital wards. De Wilde \& Coley [60] conducted a literature review investigating climate change's implication on buildings. Burman et al. [61] presented another early investigation on overheating resilience using evidence gathered from two educational buildings in London. They proposed a theoretical framework with three main criteria: vulnerability (sensitivity and exposure), resilience (capacity of response), and adaptation (long-term adjustment). Holmes et al. [62] proposed an indoor heat index for evaluating heat stress and passive habitability in residential buildings. Coley et al. [63] presented a new comfort equation for resilient building design that considers weather and probabilistic adaptive comfort measures variability. Hamdy et al. [64] investigated the impact of climate change on the overheating risk in dwellings and the potential for ventilative cooling to mitigate climate change effects. Vulnerability to overheating and sensitivity of the building response were used to assess the investigated dwellings' resilience.

Version 4.1 of the United States Green Building Council (USGBC) Leadership in Energy and Environmental Design (LEED) rating system introduced a "Thermal Resilience" pilot credit that aims to assess passive survivability and thermal resilience [65]. The credit was developed initially within the RELi rating system. RELi is a building and community rating system wholly based on resilient design [17] and has been adopted by the USGBC. Under the Thermal Resilience pilot credit, a space qualifies as thermally resilient if it can provide indoor thermal comfort in the event of a power outage. Comfort thresholds are based on standard effective temperature degree-days [66].

Table 2 summarizes documents found in the literature explicitly addressed and used the term "resilience" concerning comfort. The studies mentioned above are the beginning to define the thermal resilience of buildings. However, the studies listed in Table 2 proposed neither a consistent definition of thermal resilience nor an assessment framework for buildings' resilient cooling. The literature review confirms the need to establish a definition of resilient cooling for buildings.

\section{Conceptualization of resilient cooling for buildings}

\subsection{Resilience against what?}

One critical prerequisite for a comprehensive definition and assessment of resilience is identifying threats (shocks) or disruptions to the stability of these systems. An essential question to answer is "resilience against what?".

As shown in Table 3, several types of disruptions or emergencies can lead to buildings' systemic failure to be resilient-e.g., air 
Table 2

A list of documents found in literature in direct relation with the thermal resilience of buildings based on Appendix I

\begin{tabular}{|c|c|c|c|c|}
\hline Scientific Article & Reference & Definition Paper & Review Paper & Calculation Method \\
\hline Lomas (2009) & [58] & & & レ \\
\hline Lomas et al. (2012) & [59] & & & \\
\hline De Wilde et al. (2012) & [60] & & $\nu$ & \\
\hline Burman et al. (2014) & [61] & & & レ \\
\hline Holmes et al. (2017) & [62] & & & $\boldsymbol{r}$ \\
\hline Lomas et al. (2017) & [67] & & $\nu$ & \\
\hline Coley et al. (2017) & [63] & & & $\boldsymbol{r}$ \\
\hline Hamdy et al. (2017) & [64] & & & レ \\
\hline \multicolumn{5}{|l|}{ Rating System } \\
\hline USGBC (2018) & {$[65,66]$} & r & & r \\
\hline USGBC (2019) & [17] & $\boldsymbol{r}$ & & $\boldsymbol{r}$ \\
\hline
\end{tabular}

* Search Keywords: resilient, resilience, thermal, overheating, building

Table 3

Different types of disruptions affecting the built environment

\begin{tabular}{|c|c|}
\hline Disruption & Description \\
\hline Air Pollution & $\begin{array}{l}\text { - Outdoor air pollution refers to the air pollution experienced by populations living in and around urban areas. Air pollution derives from } \\
\text { poor combustion of fossil or biomass fuels (e.g., exhaust fumes from cars, furnaces, or wood stoves) or wildfires [69]. Buildings require } \\
\text { efficient air filters and ventilation systems that mitigate the impact of air pollution. }\end{array}$ \\
\hline Fire & $\begin{array}{l}\text { - Wildfires are sweeping and destructive conflagrations, especially in a wilderness or a rural area, that cause significant damage. Most } \\
\text { building codes adequately addresses common fire hazards with mandatory fire-resistant stairwells, fire-resistant building materials, and } \\
\text { proper escape methods. }\end{array}$ \\
\hline Earthquakes & $\begin{array}{l}\text { - Earthquakes are the most common disruptions covered in all building codes. They are trembling of the ground caused by the passage of } \\
\text { seismic waves through the earth's rocks. This natural disaster can damage a building by knocking it off its foundations and harm the } \\
\text { occupants. Seismic testing should be used on components of buildings to determine their resilience to earthquakes. }\end{array}$ \\
\hline $\begin{array}{l}\text { Wind storms and } \\
\text { hurricanes }\end{array}$ & $\begin{array}{l}\text { - Hurricane has the potential to harm lives and property via storm surge, heavy rain, or snow, causing flooding or road impassibility, } \\
\text { lightning, wildfires, and vertical wind shear. }\end{array}$ \\
\hline Flooding & $\begin{array}{l}\text { - Flooding is the inundation of land or property in a built environment, particularly in more densely populated areas, caused by rainfall } \\
\text { overwhelming the drainage systems' capacity, such as storm sewers. }\end{array}$ \\
\hline Heat waves & $\begin{array}{l}\text { - Heat waves are a period of excessively hot weather accompanied by high humidity [70]. They cause overheating in the building and } \\
\text { intensify the urban heat island effect [71]. This event can potentially risk the health and lives of occupants if no measures are taken. }\end{array}$ \\
\hline Power outages & $\begin{array}{l}\text { - Power outages and blackouts are common occurrences caused by natural disasters cited earlier, like floods or hurricanes. It can lead to } \\
\text { overheating in buildings when air conditioners do not operate. }\end{array}$ \\
\hline Water shortages & $\begin{array}{l}\text { - Water shortage is the lack of freshwater resources to meet water demand. Lack of water has a significant impact on irrigation and urban } \\
\text { use, degrading food security, public health, and overall stability. }\end{array}$ \\
\hline Pandemic & $\begin{array}{l}\text { - Pandemics can impact societies' built environment is how spatial and social aspects are intertwined to constitute everyday lives mutually. } \\
\text { During active outbreaks, such as COVID-19, minimizing the risk of disease spread in buildings starts with keeping people out of them. For } \\
\text { those who occupy a building, increasing the ventilation and filtration of the inside air is essential. }\end{array}$ \\
\hline
\end{tabular}

pollution, fires, and earthquakes. Disruptions are increasingly presented by unexpected phenomena outside or inside the building [60]. The rate and pace of disturbances that the built environment faces have been accelerating significantly over the past three decades [68]. Understanding and identifying the phenomena that disrupt a building and threaten the well-being of its occupants is fundamental.

For this study, heat waves and power outages were identified as major disruptions that can influence occupant indoor thermal quality conditions on the building scale [72]. The frequency and severity of extreme weather events have increased in the last 30 years. Increased ambient temperature during heat waves can directly influence the thermal performance of buildings by decreasing the efficiency of energy systems. This direct impact makes the extreme weather event and associated power outages major sources of disruptions for resilience evaluation. In addition to the direct impact, heat waves can have some cascading impacts such as power failure, access to clean water, and acceptable indoor air quality. There are other potential disruptions to the indoor environment detailed in Table 3. However, of these only heat waves and power outages directly affect the indoor thermal quality. For example, heat from wildfires might affect the indoor environment, but buildings are typically evacuated if a wildfire is close enough to heat them.

Therefore, the paper is focused on the definition of resilient cooling of buildings as part of the IEA-EBC Annex 80 activities that aim to define resilience. Crawley et al. [73] identified heat waves as the significant climate change disruption in buildings. Baniassadi et al. [74] identified the frequency and duration of power outages as a significant cause of disruption for buildings in the near future. Both studies confirmed that the increase of mean outdoor temperatures and the frequent and intensive nature of heat waves disrupt power and degrade comfort.

Disruptions are shocks or events with an origin, a nature, an incidence, a scale, and duration. Therefore, we define disruptions in buildings as shocks that degrade the indoor environment and require resilient cooling strategies and technologies to maintain it [60].

\subsection{Resilience: At which scale? And for how long?}

The resilience of a system cannot be studied without examining the system's scale and the relation between the shock cause and its effect(s). Resilient systems function through the interaction of complex processes operating at different scales and times frames [75]. Therefore, it is essential to characterize the scale of the system expected to be resilient in a time-bound way. The definition of resilience should always reflect whether the disturbance affects a single building element's performance or operation, building service, or the entire building [76]. As shown in Fig. 3, the definition of resilience should always characterize the resilience to disturbance of a system to its scale within a specific time frame for the distur- 


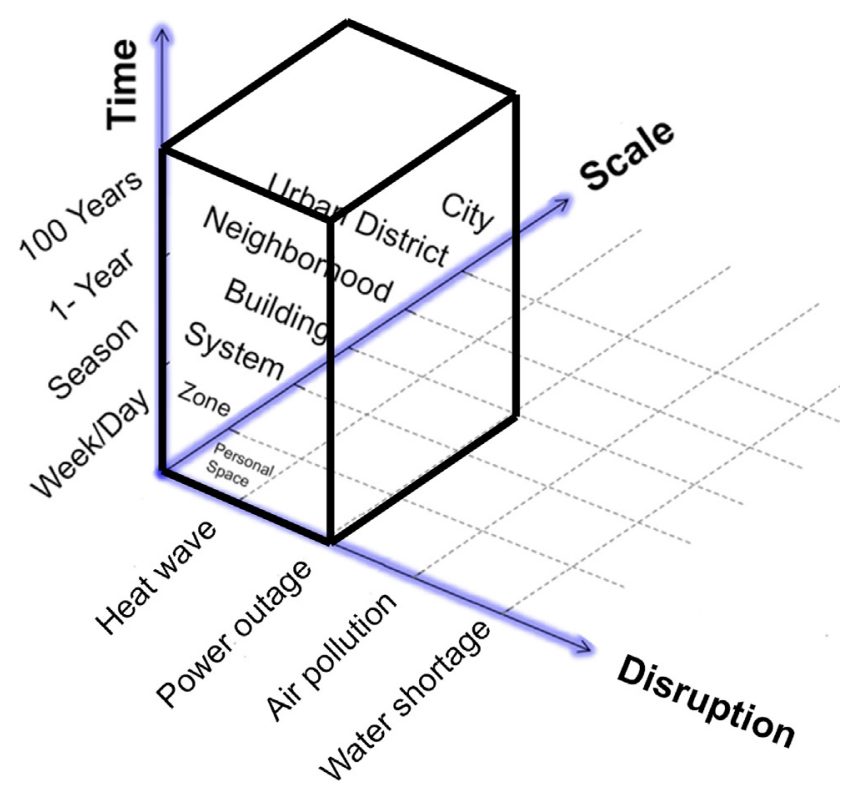

Fig. 3. the components of a resilience definition within a specific field or domain.

bance. According to Fig. 3, this study defines resilient cooling in buildings within certain boundary conditions that are limited to the building scale in response to heat waves and power outages for duration of 100 years.

We select heat waves and power outages as the primary disruptive events to be addressed by resilient cooling for buildings for our study. Our proposed definition considers the indoor environmental conditions on the building scale for long periods. Climate scenarios represent historical and future outdoor conditions and consider both short-term and long-term heat waves. Resilience in the building engineering field is strongly associated with long-term climate projections that encompass both the increase in the average temperature due to a global warming effect or temperature rise due to the urban heat island effect [77].

Defining and identifying disruptions and specifying their associated events that impact healthy and comfortable buildings is the first step to determine a building's resilience. Other issues can degrade the indoor thermal environment, such as the sudden change of indoor occupant numbers during some events. However, in this study, we focus only on climatic disruptions represented into heat waves and power outages. As shown in Fig. 3, heat waves and power outages are events that may impact the thermal conditions in buildings. The identification of heat-wave events is based on their intensity, duration, and frequency coupled with power outages [78]. It is expected that a building with a resistant cooling design (strategy) can withstand short and extensive heat waves. A building with a robust cooling design can withstand short, intense, and prolonged lengthy heat wave. The performance of a building with a resilient cooling design could surpass that of a robust building by reacting to power outages and longer intensive heat waves. The literature review confirms that resilience must be associated with response to system failure [17]. A system is robust when it can continue functioning in the presence of internal and external challenges without a system failure. However, a system is resilient when it can adapt to internal and external challenges by changing its operation method while continuing to function. The ability of the building to recover after disruptive events is a fundamental feature of resilience. Therefore, the ability to model the occurrence and consequences of discrete heat-wave events is crucial to prepare the building for the response.
The interviewed experts agreed that climate change should be defined as a long-term disruptive event and that heat waves and power outages should be designated short-term disruptive events. Based on our literature review and following Fig. 4, we distinguish four major events categories that can challenge resilient cooling [78]:

1. Event 1: Observed and future extreme weather conditions (extended, spanning years)

2. Event 2: Seasonal extreme weather conditions (extended, spanning months)

3. Event 3: Short extreme weather conditions (short, spanning days)

4. Event 4: Power outages (spanning hours)

Across the literature, several studies identified extended and long climate change associated temperature increase events (Events 1 and 2) [64,79]. Other studies investigated the impact of short-term heat waves and power outages on thermal conditions and cooling systems' resilience [80,81]. For example, the RELi rating system requires thermal safety during emergencies (Events 3 and 4 ) by maintaining indoor air temperature at or below outdoor air temperature up to seven days [17]. Designers need to demonstrate that the building will maintain safe temperatures during a blackout that lasts four days through thermal zoning and modeling. During a power outage, buildings must provide backup power to satisfy critical loads for $36 \mathrm{~h}$.

We define four major event categories that need to be tested and address in any resilience assessment for comfort in buildings. The following section provides further detailed explanation for Fig. 3 in association with Fig. 4.

\section{Definition of "resilient cooling for buildings}

Resilient cooling is used to denoting low-energy and lowcarbon cooling solutions that strengthen the ability of individuals and our community as a whole to withstand, and also prevent, the thermal and other impacts of changes in global and local climates-particularly concerning rising outdoor temperatures and the increasing frequency and severity of heat waves [61].

Resilient cooling for buildings is a concept that was not approached thoroughly in previous studies. Therefore, we developed the following definition based on the literature review and

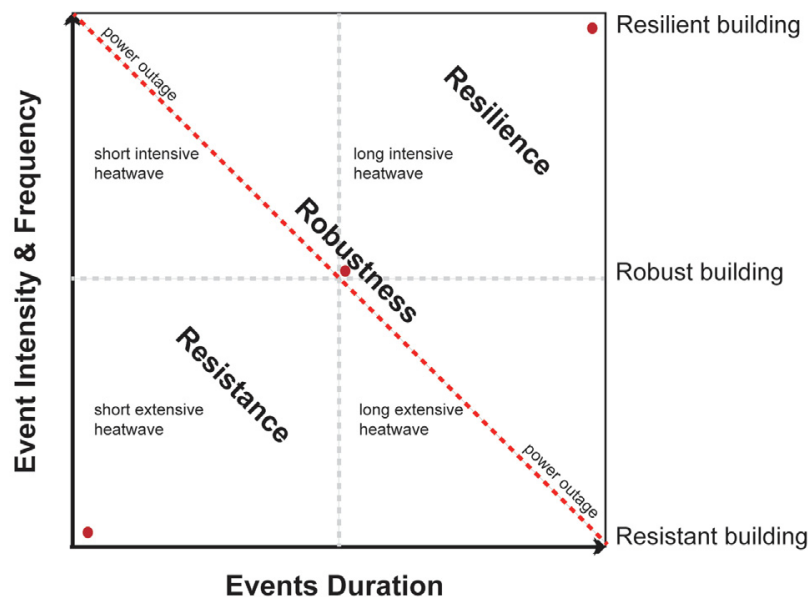

Fig. 4. The components of a resilience definition within a specific field or domain. 
validated it through the focus group discussion with members of IEA-EBC Annex 80:

The cooling of a building is resilient when the capacity of the cooling system integrated in the building allows it to withstand or recover from disturbances due to disruptions, including heat waves and power outages, and to adopt the appropriate strategies after failure (robustness) to mitigate degradation of building performance (deterioration of indoor environmental quality and /or increased need for space cooling energy (recoverability).

Resilience is a process that involves several criteria, including vulnerability, resistance, robustness, and recoverability [35]. Therefore, we include those four criteria in the definition formulation shown in Fig. 5. The vulnerability involves the sensitivity or propensity of the building's comfort conditions to different disruptions. At this stage, it is vital to define disruptions, as discussed in Sections 4.1 and 4.2 (see Figs. 3 and 4).

A resilient building must be conceived based on a vulnerability assessment that considers future climate scenarios and prepares the building system, including occupants, to adapt against failures. The vulnerability assessment should test the building performance against long-term disruptions using average weather conditions, extreme weather conditions, future weather conditions, and worst future weather conditions. It should also test the building against short-term disruptions, including brief heat waves and power outages. A vulnerability assessment stage should be part of the design process. A building cooling system is prepared to go through different disruption scenarios engaging other thermal conditions.

The building cooling system should be able to withstand shortterm and long-term disruptive events. As shown in Fig. 5, resistance involves the ability and the depth of reaction to the shock. Under disruptive events, the building may use performance dropbacks to achieve the pre-defined minimal thermal conditions. After the building cooling system's failure, the building's resilience process moves to the most crucial stage-robustness, meaning reaction to failure. Robustness requires the building to be prepared to survive an otherwise-fatal shock by adapting its performance. The survivability of the system relies on its ability to assure the critical thermal conditions to maintain occupants' functional activities during a crisis. As shown in Fig. 5, a robust building will first fail and then adapt its performance conditions meeting critical or minimum thermal requirements to achieve a degree of survivabil- ity for occupants depending on the vulnerability assessment decisions made during design. The failure time of a robust building will be relatively long before recovery, and the performance will reach only minimum thermal conditions after failure compared to a resilient building. The significant distinction between a resistant building system and a robust building system is that the latter is prepared to adapt based on a backup plan and ecosystem. Robustness involves how the building, including its services and occupants, adjusts and adapts to shocks.

The final stage of resilience involves the recoverability of the system. Recoverability consists of the extent and nature a occupants and building's services to recover, and returns to its equilibrium state and its speed to come back. As shown in Fig. 5, recovering has a duration, performance, and learnability. The necessary speed for recovery and the recovery performance curve should be planned during the vulnerability assessment stage. The users' ability, building, and systems to learn from the event is an integral part of this stage.

While the diagram in Fig. 5 is linear, the process of resilience is cyclic and iterative. Resilient cooling of buildings is a continuous process that involves the commissioning and retro-commission of building elements and systems over the building's life cycle. It also includes the continuous education of occupants and the preparation for the adaptive measures during unforeseeable disruptions.

Fig. 6 provides a complementary definition framework that includes the main criteria of resilience. It presents an example of the factors that influence cooling performance in buildings under the four resilience criteria. Depending on the overheating definition and exposure risk, a resilient cooling design for buildings assures that the designed indoor environmental conditions are secured before the disruption. The risk factors should be identified during the design stage to assess vulnerability. Examples of risk factors include climate change scenarios, heat waves combined with power outages, or urban heat island effects. As shown in Fig. 6, the resistance stage depends mainly on the building's design features and technologies and their ability to keep the building performing under severe overheating exposure until reaching failure. The failure is the essential disruption to start the third stage of resilience, namely robustness. The cooling system's robustness must adapt to cover the critical thermal conditions temporarily until reaching the recovery stage. Adaptively, the ability to respond

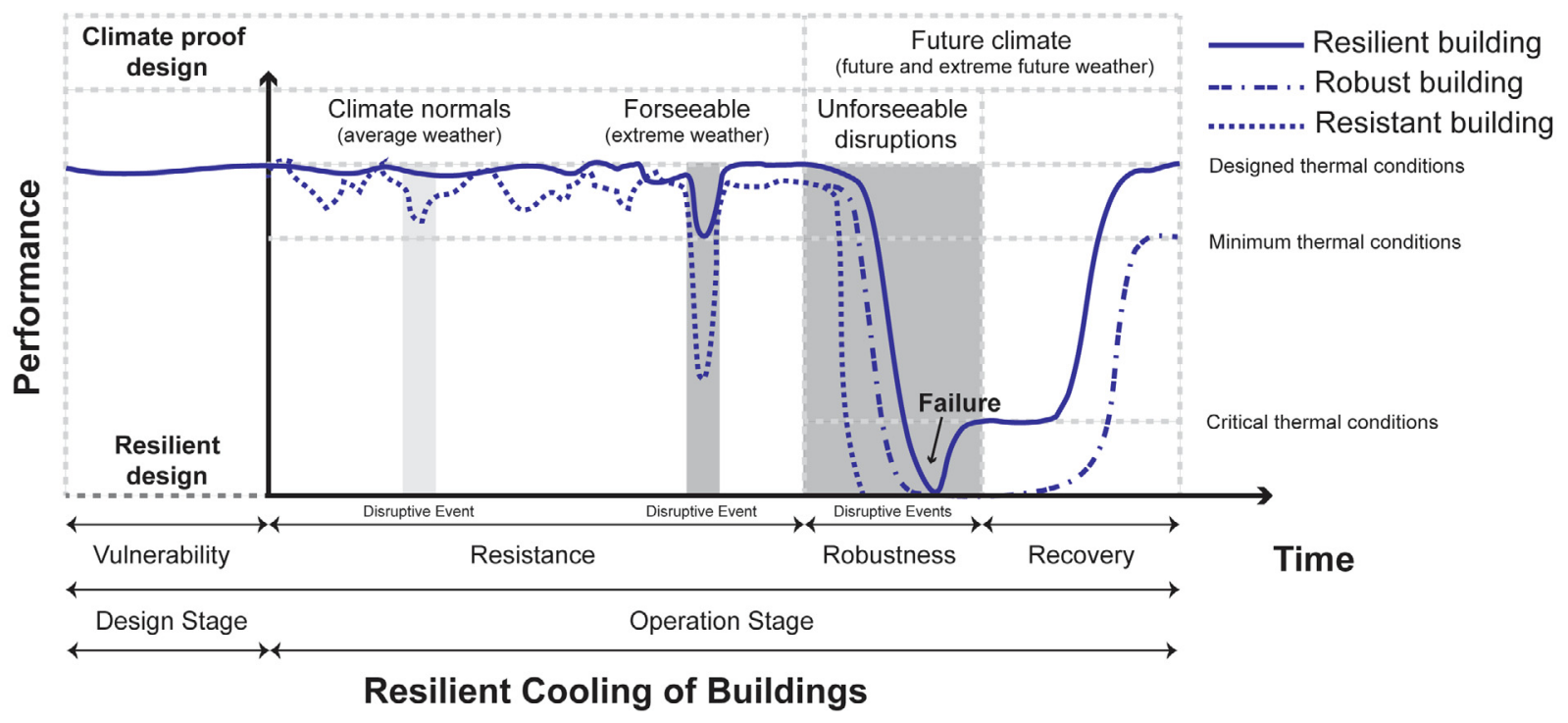

Fig. 5. The components of a resilience definition within a specific field or domain modifying Moazami et al. 's definition in 2019 [50]. 


\section{Definition of Resilient Cooling Characteristics and Risk Factors}

\begin{tabular}{|c|c|}
\hline $\begin{array}{l}\text { Resiliency } \\
\text { Characteristics }\end{array}$ & Vulnerability \\
\hline $\begin{array}{l}\text { Resilient } \\
\text { Cooling } \\
\text { Characteristics }\end{array}$ & $\begin{array}{l}\text { Overheating } \\
\text { Exposure } \\
\text { Risk }\end{array}$ \\
\hline $\begin{array}{l}\text { Risk } \\
\text { Factors }\end{array}$ & $\begin{array}{l}\text { Climate Change } \\
\text { Scenarios } \\
\text { Heat wave events } \\
\text { Power Outages } \\
\text { Urban Heat Island } \\
\text { Load Change } \\
\text { (occupancy, solar or } \\
\text { other thermal loads) }\end{array}$ \\
\hline
\end{tabular}
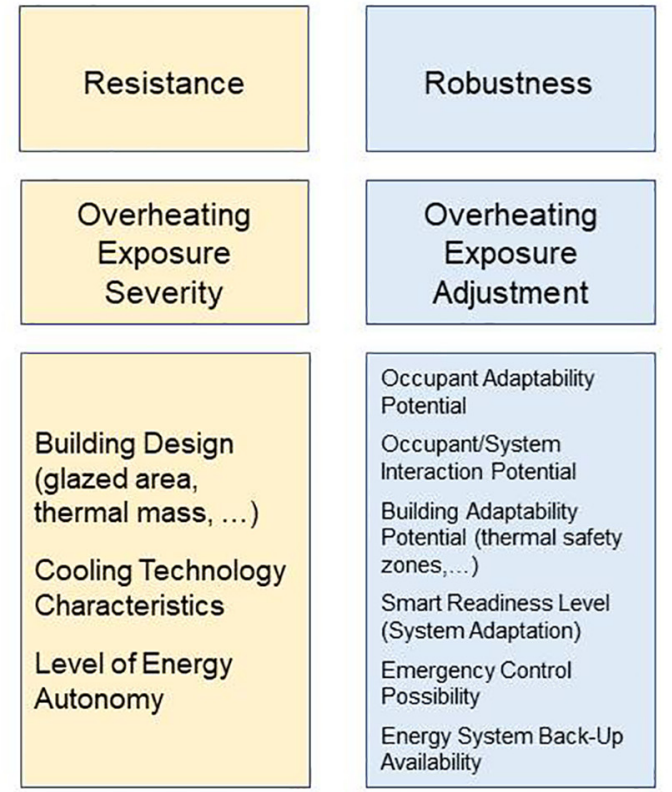

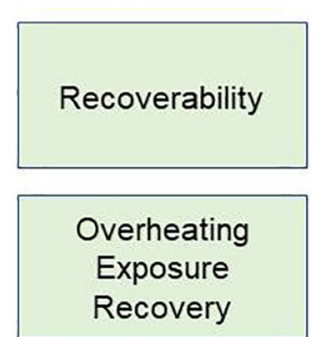

Occupant Adaptability

Potential

Occupant/System

Interaction Potential

Building Adaptability

Potential (thermal safety

zones,...)

Smart Readiness Level

(System Adaptation)

Emergency Control

Possibility

Energy System Back-Up

Availability

Fig. 6. Factors that influence resilient cooling of buildings.

and apply changes to the original thermal conditions involved occupants and systems adaptability. The presence of energy system backup and an emergency control possibility is part of the building's robustness. This is finally followed by a recovery stage and a shift in the building performance to achieve before designed thermal conditions that reflects adapting to the normal.

\section{Discussion}

The review of the main concepts on resilience mainly relates to the resilience of ecology, economy, city, and buildings. Therefore, proposing a definition for buildings and assessment framework indicates the complexity of the idea. We found varying and inconsistent definitions of resilience in building comfort and in the context of the overall built environment. The following sections discuss possible questions that we answered in this study.

- What are the existing concepts of resilience?

- How to define resilient cooling for buildings?

\subsection{Findings and recommendations}

For this study, we defined resilient cooling for buildings and developed a framework used by building designers, authorities, developers, and future occupants. By reviewing the literature, including rating systems and standards and consulting with IEAEBC Annex 80 members, USGBC members, and UN experts, the proposed definition and criteria intend to identify and group critical performance criteria of buildings cooling resilience. The criteriavulnerability, resistance, robustness, and recoverability-can help develop intrinsic performance-driven indicators and functions of passive and active cooling solutions in buildings against heat waves and power outages. In this sense, this study aimed to screen, characterize, and structure resilience criteria to provide a logical framework to design and evaluate resilient cooling strategies for buildings.
Few studies and case studies succeeded in defining resilience and applying its principles on a building scale. Across our review, we found some studies that focus mainly on robustness as a proxy for resilience $[48,50]$. However, none of those reviewed studies embraced a multi-criteria approach for resilience that involves vulnerability, resistance, robustness, and recoverability. Therefore, based on our literature review and focus group discussions, this study's suggested definition and framework is a step forward. The following recommendations can be helpful for designers and building operators that seek to achieve resilient cooling of buildings in a holistic way:

1. Any definition of resilience must be based on the identification of a specific shock or disruption. In the case of resilient cooling of buildings, heat waves and power outages are considered as the main shocks (extreme events). Designers should assess the vulnerability of buildings against those shocks.

2. Any definition of resilience should specify and distinguish, at the same time, the resistance and robustness conditions against heat waves and power outage events. The resistance period involves the building's ability to resist $\operatorname{shock}(\mathrm{s})$ with the same pre-shock operation conditions. However, robustness requires failure and adaptation after failure. The robustness mechanism involves building users and building systems adaptation and their ability to adjust after a shock.

3. Thus, the definition of resilient cooling for buildings involves four critical criteria, mainly vulnerability (sensitivity to risk), resistance (absorption), robustness (adaptation after failure), and recovery (remedy). The building design, construction, and operation processes should address these criteria.

4. Resilient cooling design is an urgent requirement for future proof buildings. Weather extremes must be anticipated to assume well-being. The choice of comfort models is elementary to prepare buildings. Resilient cooling design involves combining passive and active cooling design measures, on-site renewable production, and the coupling to storage capacities. Our suggested definition for resilient cooling of buildings can help to develop in the future resilience performance indicators that account for the impacts of glo- 
bal warming for long and short assessment periods. This can allow comparing the carbon emissions and primary energy use of different technologies at different stages of the building life stages. As part of the activities of IEA-EBC Annex 80, there is a need to assess the performance of conventional and advanced cooling technologies including advanced solar shading, chromogenic facades, cool materials, ventilated facades, thermal mass utilization including, PCM and off-peak ice storage, ventilative cooling, adiabatic/evaporative cooling, compression refrigeration, absorption refrigeration, natural heat sinks, sky radiative cooling, high-temperature cooling systems, Comfort ventilation, micro-cooling, personal comfort control and high-performance dehumidification including desiccant humidification. Without a multi-stage definition, it will be challenging to develop universal indicators that allow assessing the active and passive cooling technologies listed above.

5. Building operation systems and building management systems will play a significant role in applying the adaptation strategies and risk mitigation plans in collaboration with buildings users. For resilient cooling, HVAC systems and envelope features are a prime target for real-time optimization. Different dynamic control strategies with predictive algorithms should be embedded in building operation systems using a deeply coupled network of sensors. The smart readiness of buildings is part of resilience because it considers the fact that buildings must play an active role within the context of an intelligent energy system [82].

6. Resilience is a process, and its criteria should be addressed following a circular, iterative approach. Extracting learned lessons and integrating user experience during shocks is essential to increase the emergency learnability and feed the preparedness loop.

\subsection{Strength and limitations}

We are not aware of any studies that aimed to define resilience on a building scale involving the four criteria for resilience: vulnerability, resistance, robustness, and recovery. Two other resilience definition criteria are found in literature and are used on an urban scale: (1) adaptability, efficiency, flexibility, and redundancy; and (2) preparation, adaptation, recovery, and mitigation. However, both groups of criteria ( 1 and 2 ) hardly fit and match the indoor environmental performance requirements and challenges of buildings (and their occupants) against overheating and power outages events.

Despite the difficulty of creating a definition and developing a framework, the research benefited from the contributions of IEAEBC Annex 80 building experts, RELi steering committee members, and UN resilience experts who fostered a consensus for a new definition and framework. The debate on considering "failure "or the "path to failure" fundamental criteria in the interpretation of resilience let us distinguish robustness from resistance [41]. Accordingly, the research aimed to provide a perspective for building professionals and users based on analyzing the existing literature and body of knowledge. The study theme remains novel because it was never discussed extensively in the different fields of use of the definitions of resilience in ecology, psychology, engineering, and economy.

A definition and framework within the scope of the IEA-EBC Annex 80 was proposed and validated. The definition positions "resilient cooling "in the field of engineering and economic resilience concerning climatic disruptions, namely heat waves and power outages. As shown in Fig. 6, it identifies the main criteria and sub-criteria that can be used to design, construct, and operate new and existing buildings [35]. Content analysis of more than 90 publications was conducted to provide insights and establish relevant connections with resilience definitions found in the scientific and professional literature. RELi 2.0 Rating Guidelines for Resi- lient Design and Construction [17] and its assessment criteria were critically investigated. The identified criteria will improve the understanding of practitioners and allow for comparison, discussion, and learning. The paper developed in-depth criteria that provide valuable strategies for resilient building design. It can help researchers and designers identify and reduce the risk of overheating during heat waves and power outages to protect occupants. The definition and criteria will allow benchmarking of resilient cooling buildings, including systems, solutions, and building control strategies.

However, the most challenging search activity was to find representative case studies. At the beginning of this study, defining resilient building cooling through case studies or reference buildings similar to developing the European sustainability reporting framework Levels $[83,84]$ was planned. Failing to find case studies that addressed the concept of resilience partially or entirely forced us to define resilience first. The complexity and novelty of this concept makes its understanding, by building professional, challenging. The adoption of the resilience definition in this paper is influenced by the interpretation found in literature in engineering and economic sciences. Also, relevant publications that focus on building resilience against overheating risks could not be found. The suggested definition and framework are complete or can eliminate risks. However, they represent an adequate and initial knowledge base that can be consolidated and refined with standards and local regulations.

One of the main questions that we have answered in the resilience definition is "Resilience to what?" So, any future resilience framework must focus on a specific disruptive event. The current framework does not address all disruptions that can degrade the indoor thermal environment in one resilience evaluation framework, unless we are developing a multi-disruptive framework, which is not our case. The literature review and the experts provided insights and in-depth knowledge elaborated by the authors to develop a framework that defines resilience against "heat waves" and "power outages". The study would have benefited more from a broader focus group involving practitioners in the building industry and stakeholders of the built environment. However, the study topic remains novel because it can establish a quantitative evaluation framework for building cooling resilience.

\subsection{Implication on practice and research}

While the design for resilience is a consolidated procedure in other fields, this is not a common approach in the architectural engineering and construction industries-especially on the building scale. In this study, the resilience of building cooling and developed a framework that should be used in practice is defined. Despite the presence of RELi 2.0 Rating Guidelines for Resilient Design and Construction [17], there is a need to develop a standard that defines the resilience on the building scale concerning different disruptions. Practitioners and building professionals are confused about the term resilience, and they use it many times to replace other meanings, such as resistance or robustness. The other problem with many building designers is that they wish to assess the cooling system's resilience separately from the building and occupants. Resilience should be applied to integrated systems that involve occupants, systems, and building operators [85]. The term is related to holistic systems and cannot be used on parts of a system.

Therefore, there is a strong need to identify case studies that embrace this concept of building scale resilience. Case studies evaluating the buildings vulnerability, resistance, robustness, and recovery attributes are required to articulate and validate the resilience key performance indicators. These case studies should investigate real-time building management systems that predict 
approaching heat waves and suggest adaptation strategies following building operators and occupants [62]. At the same time, governments and green building councils should promote exemplary buildings' design and construction as showcases of resilient buildings. Rating systems such as LEED, BREEAM, DGNB, and Levels should learn from RELi 2.0 Rating Guidelines and allow the development of further projects that adopt the concept of resilience [86]. The smart readiness indicator developed by the EU could also be used to measure the resilience of the cooling of buildings. The capacity of a building to use information and communication technologies and electronic systems to adapt its buildings services operation is essential. The same applies to adapt to the occupants' needs and the grid signals to improve indoor environmental quality during heat waves and power outages [82,87].

Finally, regional priorities regarding the climatic disruptions potential and investigate the possibility of passive resistance mechanisms of buildings (e.g., ventilative cooling and thermal storage technologies) and their adaptability robustness mechanisms should be addressed. There is a need for lateral thinking and experimental research approaches to apply the concept of resilience and assess the optimal solutions for the people and the planet.

\section{Conclusions}

A definition of resilient cooling for buildings is developed and discussed in this paper as part of the IEA-EBC Annex 80 research activities. The definition's main concepts and criteria are based on qualitative research methods. The paper presents a set of recommendations to adopt the definition in practice and research. Future research should build on our findings and create more consistent frameworks with useful quantifiable indicators, quantitative metrics, and performance threshold limits. Additional definitions of overheating and modeling of overheating events are required for different building types and climates. The research should be extended to identify benchmarks and case studies with reference values, threshold ranges, and to seek tools and reporting mechanisms for buildings' resilient cooling. Our suggested framework should evolve as research and experience build a greater understanding of resilient and sustainable buildings.

\section{CRediT authorship contribution statement}

Shady Attia: . Ronnen Levinson: Conceptualization, Validation. Eileen Ndongo: Software, Data curation, Validation, Visualization. Peter Holzer: Validation. Ongun Berk Kazanci: . Shabnam Homaei: Conceptualization. Chen Zhang: . Bjarne W. Olesen: Conceptualization. Dahai Qi: . Mohamed Hamdy: . Per Heiselberg: Conceptualization, Methodology, Validation.

\section{Declaration of Competing Interest}

The authors declare that they have no known competing financial interests or personal relationships that could have appeared to influence the work reported in this paper.

\section{Acknowledgments}

We would also like to express our gratitude to all experts for sharing their pearls of wisdom with us during this research. We thank the interviewed RELi steering committee members and UN resilience experts. Also, we wish to extend our thanks to our colleagues from IEA-EBC Annex 80 , who provided insight and expertise that greatly assisted in selecting resilient criteria during the focus group discussion.

This research was partially funded by the Walloon Region under the call "Actions de Recherche Concertees 2019 (ARC)" and the project OCCuPANt, on the Impacts Of Climate Change on the indoor environmental and energy PerformAnce of buildiNgs in Belgium during summer. The authors would like to gratefully acknowledge the Walloon Region and Liege University for funding.

Finally, we would like to acknowledge the Sustainable Building Design Lab for using data processing software in this research and the valuable support during the interviews and the content analysis of data.

\section{Appendix A}

Table A-1

Table A-1

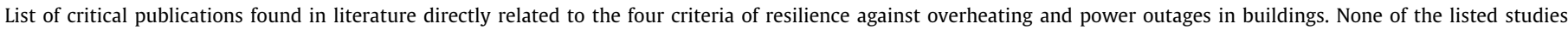
proposed a definition of resilience applied for cooling buildings except reference [55].

\begin{tabular}{|c|c|c|c|c|c|}
\hline & Vulnerability & Resistance & Robustness & Recovery & Resilience \\
\hline Sander et al. (2003) [72] & & & & & レ \\
\hline Lomas et al. $(2009,2012,2017)[58,59,67]$ & $\swarrow$ & $\nu^{*}$ & & & $\boldsymbol{\nu}$ \\
\hline De Wilde et al. (2012) [60] & & レ & & & レ \\
\hline Olsen et a. (2012) [66] & & レ & レ & 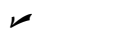 & $\nu$ \\
\hline Hassler et al. (2014) [76] & & レ & $\boldsymbol{\nu}$ & レ & $\boldsymbol{\nu}$ \\
\hline Burman et al. (2014) [61] & & レ & & & \\
\hline Anderies et al. (2014) [88] & & & & & $\boldsymbol{\nu}$ \\
\hline Nicol et al. (2014) [89] & 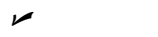 & & レ & 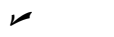 & \\
\hline Martin et al. (2015) [35] & 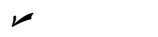 & レ & レ & 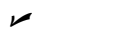 & $\boldsymbol{\nu}$ \\
\hline Buso et al. (2015) [90] & & レ & $\boldsymbol{\nu}^{*}$ & & \\
\hline Holmes et al. (2016) [62] & & レ & & & レ \\
\hline Coley et al. (2017) [63] & & $\boldsymbol{}$ & & & \\
\hline Hamdy et al. (2017) [64] & 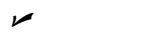 & 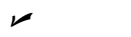 & & & \\
\hline Acione et al. (2017) [91] & & $\boldsymbol{\nu}^{*}$ & レ* & & \\
\hline Kotireddy et al. (2018) [48] & 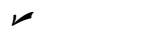 & $\nu$ & $\boldsymbol{\nu}^{*}$ & & \\
\hline Wilson (2018) [92] & 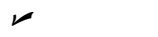 & レ & レ & レ & レ \\
\hline USGBC RELi (2018) [17] & レ & レ & $\boldsymbol{\nu}$ & レ & $\boldsymbol{\nu}$ \\
\hline USGBC (2019) [65] & & レ & $\nu$ & & レ \\
\hline Moazami et al. (2019abc) $[50,79,93]$ & 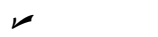 & レ & $\boldsymbol{\nu}^{*}$ & & $*$ \\
\hline Gupta et al. (2019) [94] & & $\boldsymbol{\nu}^{*}$ & & & $*$ \\
\hline Sun et al. (2020) [95] & 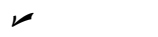 & $\nu$ & レ* & & $*$ \\
\hline Homaei et al. (2020) [49] & & & $\boldsymbol{\nu}^{*}$ & & \\
\hline
\end{tabular}

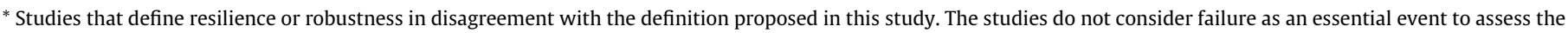
robustness and o resilience. 


\section{References}

[1] T. McAllister, T. McAllister, Developing guidelines and standards for disaster resilience of the built environment: A research needs assessment, US Department of Commerce. National Institute of Standards and Technology, 2013.

[2] A. Jacob et al., 'Transformation towards sustainable and resilient societies in Asia and the Pacific', 2018.

[3] '71/276. Report of the open-ended intergovernmental expert working group on indicators and terminology relating to disaster risk reduction', United Nations, New York, UN General Assembly 71/276 Resolution, 2017. [Online]. Available: https://www.un.org/en/ga/search/view_doc.asp?symbol=A/RES/71/ 276.

[4] European Commission, 'The European Green Deal', Brussels, Belgium, Chapter 2.1.4, 2019. Accessed: May 12, 2020. [Online]. Available: https://ec.europa.eu/ info/strategy/priorities-2019-2024/european-green-deal_en.

[5] S. Attia, Net Zero Energy Buildings (NZEB): Concepts, frameworks and roadmap for project analysis and implementation, Butterworth-Heinemann, 2018.

[6] S. Attia, Regenerative and positive impact architecture: Learning from case studies, Springer, 2018.

[7] R. Gupta, L. Barnfield, M. Gregg, Overheating in care settings: magnitude, causes, preparedness and remedies, Build. Res. Inf. 45 (1-2) (2017) 83-101.

[8] T. Kjellstrom, I. Holmer, B. Lemke, Workplace heat stress, health and productivity-an increasing challenge for low and middle-income countries during climate change, Glob. Health Action 2 (1) (2009) 2047.

[9] A. De Bono, Peduzzi, S. Kluser, and G. Giuliani, 'Impacts of summer 2003 heat wave in Europe', 2004.

[10] R. Gupta, M. Kapsali, Empirical assessment of indoor air quality and overheating in low-carbon social housing dwellings in England, UK, Adv. Build. Energy Res. 10 (1) (2016) 46-68.

[11] Holzer and Cooper, 'IEA EBC Annex 80 on Resilient Cooling for Residential and Small Non-Residential Buildings', IEA, Paris, 10.13140/RG.2.2.33912.47368, 2019. [Online]. Available: https://annex80.iea-ebc.org/Data/Sites/ 10/media/documents/supporting/ebc-annex-80-annex-text-190616.pdf.

[12] 'The Future of Cooling: Opportunities for energy-efficient air conditioning', IEA, Paris, France, 2018. [Online]. Available: https://www.iea.org/reports/thefuture-of-cooling.

[13] S. O. Andersen et al., 'Cooling Emissions and Policy Synthesis Report: Benefits of Cooling Efficiency and the Kigali Amendment Workplace', 2020.

[14] I. Kelman, J.C. Gaillard, J. Lewis, J. Mercer, Learning from the history of disaster vulnerability and resilience research and practice for climate change, Nat. Hazards 82 (1) (2016) 129-143.

[15] K.-H. Liao, 'A theory on urban resilience to floods-a basis for alternative planning practices', Ecol. Soc., vol. 17, no. 4, 2012.

[16] S.R. Carpenter, C. Folke, Ecology for transformation, Trends Ecol. Evol. 21 (6) (2006) 309-315.

[17] USGBC, RELi 2.0 Rating Guidelines for Resilient Design and Construction, U.S. Green Building Council, Washington, USA, 2018.

[18] K. Nelson, L. Gillespie-Marthaler, H. Baroud, M. Abkowitz, and D. Kosson, 'An integrated and dynamic framework for assessing sustainable resilience in complex adaptive systems', Sustain. Resilient Infrastruct., 1-19, 2019.

[19] S. Attia, A.M.E.S. Mustafa, M.K. Singh, 'Assessment of thermal overheating in free-running buildings in Cairo', in PROCEEDINGS OF THE 1ST INTERNATIONAL CONFERENCE ON COMFORT AT THE EXTREMES: ENERGY, Economy and Climate (2019) 902-913.

[20] S. Attia, S. Bilir, T. Safy, C. Struck, R. Loonen, F. Goia, Current trends and future challenges in the performance assessment of adaptive façade systems, Energy Build. 179 (2018) 165-182.

[21] S. Attia, R. Lioure, Q. Declaude, Future trends and main concepts of adaptive facade systems, Energy Sci. Eng. (2020).

[22] E. Garfield, S. Paris, W.G. Stock, HistCiteTM: A software tool for informetric analysis of citation linkage, Inf. Wiss. Prax. 57 (8) (2006) 391.

[23] G. R. Gibbs, 'Thematic coding and categorizing', Anal. Qual. Data Lond. Sage, 38-56, 2007.

[24] N.K. Gale, G. Heath, E. Cameron, S. Rashid, S. Redwood, Using the framework method for the analysis of qualitative data in multi-disciplinary health research, BMC Med. Res. Methodol. 13 (1) (2013) 117.

[25] A. Lacey, D. Luff, Qualitative data analysis, Trent Focus Sheffield (2001).

[26] S. Friese, Qualitative data analysis with ATLAS. ti. SAGE Publications Limited, 2019.

[27] S. Attia, 'Content Analysis', Qualitative Research Methods, Mar. 01, 2020. https://tinyurl.com/qorc2x3 (accessed Oct. 10, 2019).

[28] S. Attia, 'In-depth Interviews', Qualitative Research Methods, May 01, 2020. https://tinyurl.com/ycacmljt (accessed Oct. 10, 2019).

[29] S. Attia, 'Focus group discussion', Qualitative Research Methods, 2020. https:// tinyurl.com/y815xv4r (accessed Jun. 01, 2020)

[30] Holzer, 'Annex 80 Participants', Annex 80 Participants, 2019. https://annex80. iea-ebc.org/participants (accessed Jun. 01, 2020).

[31] T. Cannon, D. Müller-Mahn, Vulnerability, resilience and development discourses in context of climate change, Nat. Hazards 55 (3) (2010) 621-635.

[32] C. Folke, S. Carpenter, T. Elmqvist, L. Gunderson, C.S. Holling, B. Walker, Resilience and sustainable development: building adaptive capacity in a world of transformations, AMBIO J. Hum. Environ. 31 (5) (2002) 437-440.

[33] S.B. Manyena, The concept of resilience revisited, Disasters 30 (4) (2006) 434450.
[34] G.C. Gallopín, Linkages between vulnerability, resilience, and adaptive capacity, Glob. Environ. Change 16 (3) (2006) 293-303.

[35] R. Martin, Sunley, On the notion of regional economic resilience: conceptualization and explanation, J. Econ. Geogr. 15 (1) (2015) 1-42.

[36] C.S. Holling, Resilience and stability of ecological systems, Annu. Rev. Ecol. Syst. 4 (1) (1973) 1-23.

[37] R. Graber, F. Pichon, E. Carabine, Psychological resilience, Lond. Overseas Dev. Inst. (2015).

[38] J. Simmie, R. Martin, The economic resilience of regions: towards an evolutionary approach, Camb. J. Reg. Econ. Soc. 3 (1) (2010) 27-43.

[39] R. Boschma, Towards an evolutionary perspective on regional resilience, Reg. Stud. 49 (5) (2015) 733-751.

[40] C.M. Sgro, A.J. Lowe, A.A. Hoffmann, Building evolutionary resilience for conserving biodiversity under climate change, Evol. Appl. 4 (2) (2011) 326337.

[41] C.S. Holling, Engineering resilience versus ecological resilience, Eng. Ecol. Constraints 31 (1996) (1996) 32.

[42] Y. Jabareen, Planning the resilient city: Concepts and strategies for coping with climate change and environmental risk, Cities 31 (2013) 220-229.

[43] I. Takewaki, A. Moustafa, K. Fujita, Improving the earthquake resilience of buildings: the worst case approach, Springer Science \& Business Media, 2012.

[44] S. L. Cox, E. L. Hotchkiss, D. E. Bilello, A. C. Watson, and A. Holm, 'Bridging climate change resilience and mitigation in the electricity sector through renewable energy and energy efficiency: emerging climate change and development topics for energy sector transformation', National Renewable Energy Lab.(NREL), Golden, CO (United States), 2017.

[45] H.-M. Füssel, Vulnerability: A generally applicable conceptual framework for climate change research, Glob. Environ. Change 17 (2) (2007) 155-167.

[46] J.X. Kasperson, R.E. Kasperson, B. Turner, W. Hsieh, A. Schiller, 'Vulnerability to global environmental change', in The social contours of risk: volume II: risk analysis, in: corporations and the globalization of risk, Taylor and Francis, 2012, pp. 245-285.

[47] D.R.C. Asian, 'Living with risk, A global review of disaster reduction initiatives. Preliminary version', United Nations, 2002.

[48] R. Kotireddy, P.-J. Hoes, J.L. Hensen, A methodology for performance robustness assessment of low-energy buildings using scenario analysis, Appl. Energy 212 (2018) 428-442.

[49] S. Homaei, M. Hamdy, A robustness-based decision making approach for multi-target high performance buildings under uncertain scenarios, Appl. Energy 267 (2020) 114868.

[50] A. Moazami, S. Carlucci, S. Geving, Robust and resilient buildings: A framework for defining the protection against climate uncertainty, in: IOP Conference Series, Materials Science and Engineering 609 (2019) 072068.

[51] H. Ernstson et al., Urban transitions: on urban resilience and humandominated ecosystems, Ambio 39 (8) (2010) 531-545.

[52] S. Meerow, J. Newell, M. Stults, Defining urban resilience: A review, Landsc. Urban Plan. 147 (2016) 38-49.

[53] D.R. Godschalk, Urban hazard mitigation: creating resilient cities, Nat. Hazards Rev. 4 (3) (2003) 136-143.

[54] D. Stead, Urban planning, water management and climate change strategies: adaptation, mitigation and resilience narratives in the Netherlands, Int. J. Sustain. Dev. World Ecol. 21 (1) (2014) 15-27.

[55] A. Sharifi, Y. Yamagata, Principles and criteria for assessing urban energy resilience: A literature review, Renew. Sustain. Energy Rev. 60 (2016) 16541677.

[56] B.E. Tokgoz, A.V. Gheorghe, Resilience quantification and its application to a residential building subject to hurricane winds, Int. J. Disaster Risk Sci. 4 (3) (2013) 105-114.

[57] D. Cormie, G. Mays, and Smith, Blast effects on buildings. ICE publishing, 2019.

[58] K.J. Lomas, Y. Ji, Resilience of naturally ventilated buildings to climate change: Advanced natural ventilation and hospital wards, Energy Build. 41 (6) (2009) $629-653$.

[59] K.J. Lomas, R. Giridharan, Thermal comfort standards, measured internal temperatures and thermal resilience to climate change of free-running buildings: A case-study of hospital wards, Build. Environ. 55 (2012) 57-72.

[60] De Wilde, D. Coley, The implications of a changing climate for buildings, Elsevier (2012).

[61] E. Burman, J. Kimpian, and D. Mumovic, 'Reconciling Resilience and Sustainability in Overheating and Energy Performance Assessments of Nondomestic Buildings', 2014.

[62] S.H. Holmes, T. Phillips, A. Wilson, Overheating and passive habitability: indoor health and heat indices, Build. Res. Inf. 44 (1) (2016) 1-19.

[63] D. Coley, M. Herrera, D. Fosas, C. Liu, M. Vellei, Probabilistic adaptive thermal comfort for resilient design, Build. Environ. 123 (2017) 109-118.

[64] M. Hamdy, S. Carlucci, P.-J. Hoes, J.L. Hensen, The impact of climate change on the overheating risk in dwellings-A Dutch case study, Build. Environ. 122 (2017) 307-323.

[65] USGBC, Leadership in energy and environmental design v4 (2019) 1.

[66] E. Olsen, J. Kuo, and A. Tazi, 'Resilient Design: Putting thermal resilience in the LEED pilot credits to the test', 2012. https://www.resilientdesign.org/puttingthermal-resilience-in-the-leed-pilot-credits-to-the-test/.

[67] K.J. Lomas, S.M. Porritt, Overheating in buildings: lessons from research, Taylor \& Francis, 2017.

[68] L. Bull-Kamanga et al., From everyday hazards to disasters: the accumulation of risk in urban areas, Environ. Urban. 15 (1) (2003) 193-204. 
[69] W. H. Organization, 'Background information on urban outdoor air pollution', WHO Accessed April, vol. 21, 2017.

[70] S. Carlucci, L. Pagliano, A review of indices for the long-term evaluation of the general thermal comfort conditions in buildings, Energy Build. 53 (2012) 194205.

[71] C. Di Napoli, F. Pappenberger, H.L. Cloke, Verification of Heat Stress Thresholds for a Health-Based Heat-Wave Definition, J. Appl. Meteorol. Climatol. 58 (6) (2019) 1177-1194

[72] C.H. Sanders, M.C. Phillipson, UK adaptation strategy and technical measures: the impacts of climate change on buildings, Build. Res. Inf. 31 (3-4) (2003) 210-221.

[73] A. Jones, Indoor air quality and health, Atmosph. Environ. 33 (28) (1999) 45354564.

[74] A. Baniassadi, J. Heusinger, D.J. Sailor, Energy efficiency vs resiliency to extreme heat and power outages: The role of evolving building energy codes, Build. Environ. 139 (2018) 86-94.

[75] T. Swanstrom, 'Regional resilience: a critical examination of the ecological framework', working paper, 2008

[76] U. Hassler, N. Kohler, Resilience in the built environment, Taylor \& Francis, 2014.

[77] M. Palme, L. Inostroza, G. Villacreses, A. Lobato-Cordero, C. Carrasco, From urban climate to energy consumption. Enhancing building performance simulation by including the urban heat island effect, Energy Build. 145 (2017) 107-120.

[78] A. Laouadi, A. Gaur, M.A. Lacasse, M. Bartko, M. Armstrong, Development of reference summer weather years for analysis of overheating risk in buildings, J. Build. Perform. Simul. 13 (3) (2020) 301-319.

[79] A. Moazami, V. Nik, S. Carlucci, and S. Geving, 'Impacts of the future weather data type on the energy simulation of buildings-Investigating long-term patterns of climate change and extreme weather conditions', 2019.

[80] D.J. Sailor, Risks of summertime extreme thermal conditions in buildings as a result of climate change and exacerbation of urban heat islands, Build. Environ. 78 (2014) 81-88.

[81] C.A. MacKenzie, K. Barker, Empirical data and regression analysis for estimation of infrastructure resilience with application to electric power outages, J. Infrastruct. Syst. 19 (1) (2012) 25-35.
[82] T. Märzinger, D. Österreicher, Supporting the Smart Readiness Indicator-A Methodology to Integrate A Quantitative Assessment of the Load Shifting Potential of Smart Buildings, Energies 12 (10) (1955) 2019.

[83] A.S. Cordero, S.G. Melgar, J.M.A. Márquez, Green Building Rating Systems and the New Framework Level (s): A Critical Review of Sustainability Certification within Europe, Energies 13 (1) (2019) 1-25.

[84] N. Dodd, S. Donatello, E. Garbarino, and M. Gama-Caldas, 'Identifying macroobjectives for the life cycle environmental performance and resource efficiency of EU buildings', JRC EU Comm. Luxemb., 117, 2015.

[85] K. Beckmann and S. Roaf, 'Workshop Report: Climate Resilience for the Scottish Built Environment', in Report for ClimateXChange Scotland, 2013.

[86] N. Dodd, M. Cordella, M. Traverso, S. Donatello, Level (s)-A common EU framework of core sustainability indicators for office and residential buildings, JRC Sci. Policy ReEur. Comm. (2017).

[87] E. Parliament, Directive 2018/844/EU of the European Parliament and of the council of 19 June 2018 on the energy performance of buildings (recast), Off. J. Eur. Communities 61 (156) (2018) 75-91.

[88] J.M. Anderies, Embedding built environments in social-ecological systems: resilience-based design principles, Build. Res. Inf. 42 (2) (2014) 130-142.

[89] L.A. Nicol, Knoepfel,, Resilient housing: a new resource-oriented approach, Build. Res. Inf. 42 (2) (2014) 229-239.

[90] T. Buso, V. Fabi, R.K. Andersen, S. Corgnati, Occupant behaviour and robustness of building design, Build. Environ. 94 (2015) 694-703.

[91] F. Ascione, N. Bianco, R.F. De Masi, G.M. Mauro, G. Vanoli, Resilience of robust cost-optimal energy retrofit of buildings to global warming: A multi-stage, multi-objective approach, Energy Build. 153 (2017) 150-167.

[92] A. Wilson, 'Resilience as a driver of passive design', in Activism in Architecture, Routledge (2018) 155-164.

[93] A. Moazami, S. Carlucci, V.M. Nik, S. Geving, Towards climate robust buildings: An innovative method for designing buildings with robust energy performance under climate change, Energy Build. 202 (2019) 109378.

[94] R. Gupta, A. Bruce-Konuah, A. Howard, Achieving energy resilience through smart storage of solar electricity at dwelling and community level, Energy Build. 195 (2019) 1-15.

[95] K. Sun, M. Specian, T. Hong, Nexus of thermal resilience and energy efficiency in buildings: A case study of a nursing home, Build. Environ. 106842 (2020). 